\title{
REKOMENDASI PEMBELIAN PERSONAL KOMPUTER DENGAN METODE RANKED CLUSTERING
}

\author{
Fadly Shabir ${ }^{1}$ dan Abdul Rachman $\mathbf{M}^{2}$

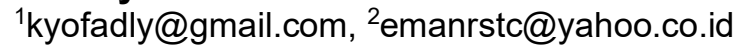 \\ ${ }^{1}$ Stimik Handayani, ${ }^{2}$ Universitas Muslim Indonesia
}

\begin{abstract}
Abstrak
Perkembangan teknologi berdampak pada persaingan perusahaan yang cukup ketat, produksi yang beragam dan variatif membuat produk komputer memiliki banyak spesifikasi yang berbeda, tentu hal itu akan semakin menyulitkan bagian pemasaran dalam mempromosikan produk komputer. Penelitian ini bertujuan untuk merekomendasikan komputer dengan spesifikasi yang diinginkan oleh calon pembeli, dengan cara menganalisa basis data produk komputer untuk kemudian di klasifikasi berdasarkan karakteristik tertentu. Implementasi Recommendation system ini menggunakan algoritma AHP dan algoritma K-means, dimana metode untuk proses ranking menggunakan AHP dengan menganalisa basis data produk komputer dan analisis kluster untuk mengelompokkan individu atau objek menjadi beberapa kelompok yang sama mempunyai kemiripan satu dengan yang lain di bandingkan dengan anggota cluster lain. Hasil dari kombinasi algoritma AHP dan K-Means yaitu rekomendasi produk komputer lebih variatif. Pengolahan data menggunakan kombinasi algoritma AHP dan K-Means menghasilkan rekomendasi produk kepada pengguna yang lebih heterogen dibandingkan dengan rekomendasi produk dari data yang diolah hanya menggunakan algoritma AHP tanpa di-cluster K-Means. Sehingga dapat ditarik kesimpulan bahwa proses clustering akan menghasilkan kaidah-kaidah asosiasi dengan kualitas yang lebih baik.
\end{abstract}

Kata kunci: Personal komputer, Ranking, Klaster, Data Mining.

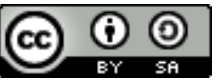

ILKOM Jurnal IImiah work is licensed under a CCA-SA 4.0 International License.

\section{Pendahuluan}

Perkembangan teknologi berdampak pada persaingan perusahaan yang cukup ketat. Strategi yang tepat sangat diperlukan dari segala aspek termasuk aspek produk, proses dan jadwal. Permasalahan industri tidak hanya menyangkut seberapa besar investasi yang harus ditanam, sistem dan prosedur produksi, pemasaran hasil produksi dan lain lain. Produksi yang beragam dan variatif membuat produk komputer memiliki banyak spesifikasi yang berbeda, tentu hal itu akan semakin menyulitkan bagian pemasaran dalam mempromosikan produk komputer dikarenakan banyaknya jenis komputer yang harus mereka hafal disertai spesifikasi yang berbeda-beda.

Semakin variatifnya jenis komputer juga akan semakin menyulitkan dan membingungkan calon pembeli dikarenakan harus membandingkan spesifikasi yang begitu banyak dari berbagai merek komputer. Sehingga dibutuhkan sebuah aplikasi yang dapat merekomendasikan komputer dengan spesifikasi yang diinginkan oleh calon pembeli, dengan cara menganalisa basis data produk komputer untuk kemudian di klasifikasi berdasarkan karakteristik tertentu].

Permasalahan yang ditemukan adalah belum adanya sistem yang mampu memudahkan calon pembeli atau pengguna untuk menentukan jenis produk personal komputer yang akan mereka beli. bagaimana membangun aplikasi yang dapat

Oleh karena itu diperlukan adanya skema rancangan sistem yang mampu berfungsi sebagai alat bantu, dengan kata lain memungkinkan untuk merekomendasikan pada calon pembeli suatu produk personal komputer dengan menganalisa basis data dan menggunakan pendekatan data mining.

\section{Landasan Teori}

Data mining, sering juga disebut knowledge discovery in database (KDD) adalah kegiatan yang meliputi pengumpulan, pemakaian data historis untuk menemukan keteraturan, pola atau hubungan dalam set data berukuran besar. Keluaran dari data mining ini bisa dipakai untuk memperbaiki pengambilan keputusan di masa depan [1].

\subsection{Teknik Data Mining}

Definisi data mining yang begitu luas, ada banyak jenis metode analisis yang dapat digolongkan dalam data mining[2]: 
1. Classification,metode yang paling umum pada data mining. Persoalan bisnis seperti Churn Analysis, dan Risk Management biasanya melibatkan metode Classification. Classification adalah tindakan untuk memberikan kelompok pada setiap keadaan. Setiap keadaan berisi sekelompok atribut, salah satunya adalah class attribute. Metode ini perlu untuk menemukan sebuah model yang dapat menjelaskan class attribute itu sebagai fungsi dari input attribute.

2. Clustering,Clustering juga disebut sebagai segmentation. Metode ini digunakan untuk mengidentifikasi kelompok alami dari sebuah kasus yang didasarkan pada sebuah kelompok atribut, mengelompokkan data yang memiliki kemiripan atribut. Kebanyakan Algoritma Clustering membangun sebuah model melalui serangkaian pengulangan dan berhenti ketika model tersebut telah memusat atau berkumpul (batasan dari segmentasi ini telah stabil).

3. Association, juga disebut sebagai Market Basket Analysis. Sebuah problem bisnis yang khas adalah menganalisa tabel transaksi penjualan dan mengidentifikasi produk-produk yang seringkali dibeli bersamaan oleh customer.

4. Regression,Metode Regression mirip dengan metode Classification, yang membedakannya adalah metode regression tidak bisa mencari pola yang dijabarkan sebagai class (kelas). Metode regression bertujuan untuk mecari pola dan menentukan sebuah nilai numerik.

5. Forecasting, Sebagai inputnya teknik Forecasting akan mengambil sederetan angka yang menunjukkan nilai yang berjalan seiring dengan waktu dan kemudian teknik Forecasting ini akan menghubungkan nilai masa depan dengan menggunakan bermacam-macam teknik machinelearning dan teknik statistik yang berhubungan dengan musim, trend, dan noise pada data.

6. Sequence Analysis, digunakan untuk mencari pola pada serangkaian kejadian yang disebut dengan sequence.

7. Deviation Analysis, digunakan untuk mencari kasus yang bertindak sangat berbeda dari normalnya.

\subsection{Algoritma K-means.}

K-means merupakan salah satu metode data clustering non-hirarki yang berusaha mempartisi data yang ada ke dalam bentuk satu atau lebih clusteri kelompok. Metode ini mempartisi ke dalam clusteri kelompok sehingga data yang memiliki karakteristik yang sama (high intra-class similarity) dikelompokkan ke dalam satu cluster yang sama dan yang memiliki karakteristik yang berbeda (low Inter-class similarity) dikelompokkan pada kelompok yang lain. Proses clustering dimulai dengan mengidentifikasi data yang akan dicluster, $x_{i j}(i=1, \ldots, n ; j=1, \ldots, m)$ dengan $\mathrm{n}$ adalah jumlah data yang akan dikluster dan $\mathrm{m}$ adalah jumlah variabel. Pada awal iterasi, pusat setiap kluster ditetapkan secara bebas (sembarang), $c_{k j}(k=1, \ldots, k ; j=1, \ldots, m)$. Kemudian dihitung jarak antara setiap data dengan setiap pusat cluster [3].

Algoritma dasar dalam k-means adalah[4]

1. Tentukan jumlah kluster (k), tetapkan pusat kluster sembarang.

2. Hitung jarak setiap data ke pusat kluster menggunakan persamaan

$$
d_{i k}=\sqrt{\sum_{j=1}^{m}\left\{x_{i j-c_{k j}}\right\}^{2}}
$$

3. Kelompokkan data ke dalam kluster yang dengan jarak yang paling pendek menggunakan persamaan

$$
\min \sum_{k=1}^{k} d_{i k}
$$

4. Hitung pusat kluster yang baru menggunakan persamaan

$$
c_{k j}=\frac{1}{p} \sum_{i=1}^{p} x_{i j}
$$

Langkah 2 sampai dengan 4 akan diulangi sehingga tidak ada lagi data yang berpindah ke kluster yang lain.

\subsection{Analytic Hierarchy Process (AHP)}

Metode AHP ini membantu memecahkan persoalan yang kompleks dengan menstruktur suatu hirarki kriteria, pihak yang berkepentingan, hasil dan dengan menarik berbagai pertimbangan guna mengembangkan bobot atau prioritas. Metode ini juga menggabungkan kekuatan dari perasaan dan logika yang bersangkutan pada berbagai persoalan, lalu mensintesis berbagai pertimbangan yang beragam menjadi hasil yang cocok dengan perkiraan kita secara intuitif sebagaimana yang dipresentasikan pada pertimbangan yang telah dibuat[5].

Tahapan - tahapan proses dalam metode AHP adalah :

1. Mendefinisikan masalah dan menentukan tujuan yang diinginkan.

2. Membuat struktur hirarki yang diawali dengan tujuan umum dilanjutkan dengan kriteria-kriteria dan alternatif-alternatif lain.

3. Membentuk matriks keputusan atau matriks perbandingan berpasangan yang menggambarkan pengaruh setiap elemen terhadap masing-masing kriteria. 
4. Menguji konsistensi hirarki. Jika nilai konsistensi rasio yang dihasilkan tidak memenuhi standar yang ditetapkan yaitu consistency ratio $(\mathrm{CR})<0,1$ maka penilaian harus diulang kembali.

\section{Metode}

\subsection{Analisa Sistem}

Dalam merancang suatu sistem diperlukan analisis terhadap sistem yang akan dirancang terlebih dahulu. Tujuan dari analisis ini sendiri adalah agar sistem yang dirancang menjadi tepat guna dan ketahanan dari sistem tersebut akan lebih terjaga [6]. Dengan dilakukannya analisis terhadap system yang akan dikembangkan dapat mempermudah dalam merancang suatu sistem, serta membantu dalam tahap perawatan, perbaikan dan perubahan.

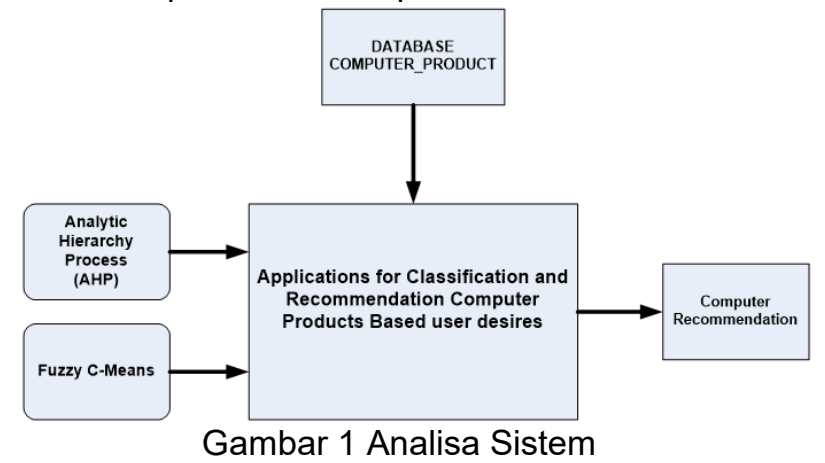

\subsection{Perancangan Prosedure}

Perancangan procedure pada sistem yang dibangun dapat diilustrasikan melalui diagram dibawah ini

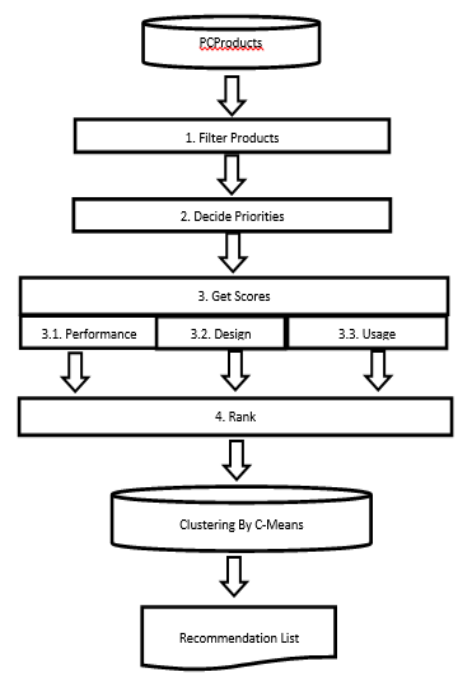

Gambar 2 Diagram Sistem

Penjelasan diagram adalah:

1. Filter Produk,pada tahap ini aplikasi akan melakukan filterisasi terhadap harga, performa, desain dan jenis pemakaian dari komputer yang dibutuhkan calon pengguna.

2. Menentukan Prioritas Kriteria,dalam tahap ini penentuan bobot prioritas menggunakan metode Analytic Hierarchy Process. Pembobotan dilakuan dengan membandingkan tiga criteria yaitu Performa, Desain dan jenis pemakian. Untuk pembobotan peneliti menggunakan sembilan variabel perbandingan yaitu Left Side is Extreme Important, Left side is Very Important. Left side is important, left side is moderate important, left side and right side are equal, Right side is moderate Important, Right side is important, right side very important, Right side is extreme important. Dengan masing-masing kriteria memiliki bobot $9,7,5,3,1,1 / 3,1 / 5,1 / 7,1 / 9$

3. Mendapatkan Computer Score, pada tahap ini untuk mendapatkan skor dari komputer, akan dihitung menggunakan metode AHP berdasarkan Performa, Desain dan Tujuan Pemakaian.

4. Mendapatkan Ranking Komputer, untuk mengetahui Rangking dari spesifikasi computer, harus dihitung skor masing masing produk berdasarkan spesifikasi dengan rumus

$$
s=(W p * S p)+(W d * S d)+(W u * S u)
$$




$$
S p=\sum_{i=1}^{4} S p_{i}
$$

5. Pada tahap ini hasil pembobotan yang telah didapat menggunakan AHP akan di cluster untuk mengklasifilasi berdasarkan karakteristik bobot masing-masing komputer menggunakan algoritma k-means.

4. Hasil

\subsection{Skenario Sistem}

1. Filter Produk,pada tahap ini aplikasi akan melakukan filterisasi terhadap harga, performa, desain dan jenis pemakaian dari komputer yang dibutuhkan calon pengguna.

2. Menentukan Prioritas Kriteria,dalam tahap ini penentuan bobot prioritas menggunakan metode Analytic Hierarchy Process. Pembobotan dilakuan dengan membandingkan tiga criteria yaitu Performa, Desain dan jenis pemakian. Untuk pembobotan peneliti menggunakan sembilan variabel perbandingan yaitu Left Side is Extreme Important, Left side is Very Important. Left side is important, left side is moderate important, left side and right side are equal, Right side is moderate Important, Right side is important, right side very important, Right side is extreme important. Dengan masing-masing kriteria memiliki bobot $9,7,5,3,1,1 / 3,1 / 5,1 / 7,1 / 9$.Seperti gambar dibawah ini.

\begin{tabular}{|c|c|c|c|c|c|c|c|c|c|c|}
\hline \begin{tabular}{l|}
$\begin{array}{c}\text { Criteria } \\
\text { evaluation }\end{array}$ \\
\end{tabular} & \begin{tabular}{|l|} 
Left side is \\
extreme \\
Important
\end{tabular} & \begin{tabular}{|c|} 
Leff side is \\
very \\
important
\end{tabular} & \begin{tabular}{|l|} 
Left side is \\
important
\end{tabular} & \begin{tabular}{|l} 
Leff side is \\
moderate \\
important
\end{tabular} & \begin{tabular}{|l} 
Left side and \\
rightside are \\
equal
\end{tabular} & $\begin{array}{l}\text { Rightside is is } \\
\text { moderate } \\
\text { Important }\end{array}$ & $\begin{array}{l}\text { Rights side is } \\
\text { Importent }\end{array}$ & $\begin{array}{l}\text { Right side is } \\
\text { very } \\
\text { important }\end{array}$ & \begin{tabular}{|c|} 
Rightside is \\
extreme \\
important
\end{tabular} & \begin{tabular}{|c|c} 
Critteria \\
evaluation
\end{tabular} \\
\hline Question 1 & 9 & 7 & 5 & 3 & 1 & $1 / 3$ & $1 / 5$ & 1/7 & $1 / 9$ & \\
\hline Performance & 0 & 0 & 0 & 0 & 0 & 0 & 0 & 0 & 0 & Design \\
\hline & & 7 & & 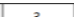 & & 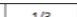 & 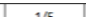 & & 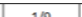 & \\
\hline Performance & $=0$ & 0 & 0 & 0 & 0 & 0 & 0 & 0 & 0 & Usage \\
\hline \begin{tabular}{|l|} 
Question 3 \\
\end{tabular} & 9 & 7 & 5 & 3 & 1 & $1 / 3$ & $1 / 5$ & $1 / 7$ & $1 / 9$ & \\
\hline Design & 0 & 0 & 0 & 0 & 0 & 0 & 0 & 0 & 0 & Usage \\
\hline
\end{tabular}

Gambar 3 Desain input Penentuan bobot prioritas criteria

3. Mendapatkan Computer Score, pada tahap ini untuk mendapatkan skor dari komputer, akan dihitung menggunakan metode AHP berdasarkan Performa, Desain dan Tujuan Pemakaian.

3.1. Mendapatkan Bobot Performa Komputer (Sp)

Bobot Performa di dapat dari empat spesifikasi yaitu CPU,GPU,Memory dan HDD. Ke empat perangkat tersebut di tentukan bobot berdasarkan kapasitas.

3.2. Mendapatkan Bobot Desain Komputer (Sd)

Ada dua variabel yang digunakan dalam penentuan bobot desain yaitu Merek Komputer / Pembuat dan ukuran, merek komputer tidak relevan untuk diberikan bobot karena tidak bisa mengukur apakah sebuah produk itu lebih baik dari produk lain hanya berdasarkan pembuatnnya. Sedangkan untuk bobot ukuran akan bernilai 1 bila terpilih dan bernilai 0 bila tidak terpilih.

3.3. Mendapatkan Bobot Fungsi Pemakaian Komputer (Sd)

Untuk menentukan bobot fungsi pemakaian peneliti mereferensi dari hasil penelitian seperti tabel di bawah ini

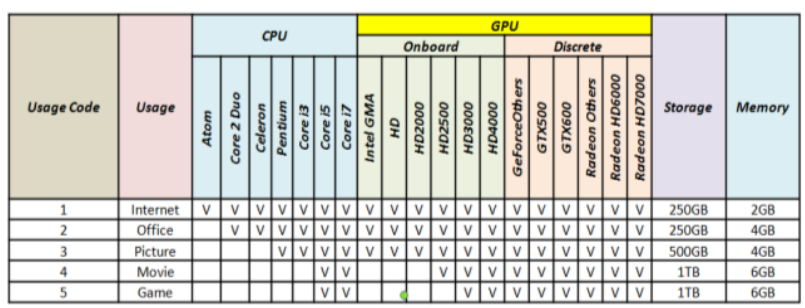

Gambar 4 Spesifikasi fungsi pemakaian computer

4. Mendapatkan ranking komputer, untuk mengetahui ranking dari spesifikasi komputer, harus dihitung skor masing masing produk berdasarkan spesifikasi dengan rumus

$$
\begin{gathered}
s=(W p * S p)+(W d * S d)+(W u * S u) \\
S p=\sum_{i=1}^{4} S p_{i}
\end{gathered}
$$


5. Pada tahap ini hasil pembobotan yang telah didapat menggunakan AHP akan di cluster untuk mengklasifilasi berdasarkan karakteristik bobot.

Skenario:

Tabel 1 Produk Komputer

\begin{tabular}{|c|l|c|c|c|c|c|c|}
\hline No & \multicolumn{1}{|c|}{ Nama Komputer } & CPU & GPU & Memory & HDD & Size & Usage \\
\hline 1 & $\begin{array}{l}\text { LuvMachines Lm- } \\
\text { iH532S Windows8 }\end{array}$ & Core i7 & HD400 & $4 G B$ & $500 G B$ & Tower & Picture \\
\hline 2 & $\begin{array}{l}\text { Amphis BTO Di } \\
\text { MD7300-Ci7-EX }\end{array}$ & Core i7 & HD400 & $8 G B$ & $1 \mathrm{~TB}$ & Compact & Movie \\
\hline 3 & $\begin{array}{l}\text { NEXXGEAR } \\
\text { i620SA7-2377HDS- } \\
\text { KK }\end{array}$ & Core i7 & $\begin{array}{l}\text { GeForce } \\
\text { GTX500 }\end{array}$ & $8 \mathrm{~GB}$ & $1 \mathrm{~TB}$ & Tower & Games \\
\hline 4 & $\begin{array}{l}\text { Think Centre M72e } \\
\text { Tower 0896CTO }\end{array}$ & Core i5 & HD250 & $4 \mathrm{~GB}$ & $1 \mathrm{~TB}$ & Tower & Picture \\
\hline 5 & $\begin{array}{l}\text { Pavilion Desktop PC } \\
\text { h8-1360jp/CT }\end{array}$ & Core i5 & HD250 & $8 \mathrm{~GB}$ & $1 \mathrm{~TB}$ & All in One & Movie \\
\hline 6 & $\begin{array}{l}\text { Compaq Elite 8300 } \\
\text { MT/CT }\end{array}$ & Core i3 & HD250 & $2 \mathrm{~GB}$ & $500 \mathrm{~GB}$ & All in One & Picture \\
\hline 7 & Asus Inspiron 660 & Core i3 & HD2000 & $4 \mathrm{~GB}$ & $500 \mathrm{~GB}$ & Compact & Picture \\
\hline 8 & Asus CP3130 & $\begin{array}{l}\text { Pentium } \\
\text { Dual- } \\
\text { core }\end{array}$ & HD & $4 \mathrm{~GB}$ & $500 \mathrm{~GB}$ & All in One & Picture \\
\hline 9 & $\begin{array}{l}\text { ThinkCentre M72e } \\
\text { Tower 0896CTO }\end{array}$ & $\begin{array}{l}\text { Geleron } \\
\text { G460 }\end{array}$ & HD & $2 \mathrm{~GB}$ & $250 \mathrm{~GB}$ & Tower & Office \\
\hline 10 & $\begin{array}{l}\text { EeeBox PC } \\
\text { EB1501P B0047 }\end{array}$ & $\begin{array}{l}\text { Atom } \\
\text { D425 }\end{array}$ & $\begin{array}{l}\text { Intel } \\
\text { GMA }\end{array}$ & $2 \mathrm{~GB}$ & $320 \mathrm{~GB}$ & All in One & Internet \\
\hline
\end{tabular}

Bobot Komputer (Ps) dapat dihitung sebagai berikut :

Komputer 1:

Bobot PerformaSp $p_{1}=$ Core $i 7 \rightarrow 0.46$

$S p_{2}=H D 250 \rightarrow 0.16$

$$
\begin{gathered}
S p_{3}=\quad 4 G B \rightarrow 0.16 \\
S p_{4}=500 G B \rightarrow 0.07 \\
S p=\frac{(0.46+0.16+0.16+0.07)}{4} \\
S p=0.213
\end{gathered}
$$

Bobot Desain : $S d=$ Tower $\rightarrow 1$

Bobot Fungsi Pemakaian Su $=$ Picture $\rightarrow 0.16$

Bobot Komputer

$$
\begin{gathered}
P s=(W p * S p)+(W d * S d)+(W u * S u) \\
P s=(0.46 * 0.213)+(0.20 * 1)+(0.34 * 0.16) \\
P s=0.098+0.20+0.055 \\
P s=0.353
\end{gathered}
$$

\begin{tabular}{|c|c|c|c|c|c|}
\hline No & Nama Komputer & $W p * S p$ & $\left|W d^{*} S d\right|$ & Wu ${ }^{*} \mathrm{Su} \mid$ & Ps \\
\hline 1 & LuYMachines Lm-iH532S Windows8 & 0.098 & 0.2 & 0.055 & 0.353 \\
\hline 2 & Amphis BTO Di MD7300-Ci7-EX & 0.123 & 0.2 & 0.097 & 0.42 \\
\hline 3 & NEXTGEAR i620SA7-2377HDS-KK & 0.138 & 0.2 & 0.157 & 0.495 \\
\hline 4 & Think Centre M72e Tower 0896СTO & 0.089 & 0.2 & 0.055 & 0.446 \\
\hline 5 & Pavilion Desktop PC h8-1360jp/CT & 0.104 & 0.2 & 0.097 & 0.401 \\
\hline 6 & Compaq Elite $8300 \mathrm{MT} / \mathrm{CT}$ & 0.064 & 0.2 & 0.055 & 0.319 \\
\hline 7 & Asus Inspiron 660 & 0.064 & 0.2 & 0.055 & 0.319 \\
\hline 8 & Asus CP 3130 & 0.046 & 0.2 & 0.038 & 0.284 \\
\hline 9 & ThinkCentre M72e Tower 0896CTO & 0.036 & 0.2 & 0.024 & 0.26 \\
\hline 10 & EeeBox PC EB1501P B0047 & 0.019 & 0.2 & 0.004 & 0.223 \\
\hline
\end{tabular}

Sehingga menghasilkan tabel berdasarkan bobot komputer (Ps) seperti dibawah ini

Tabel 2 Bobot Komputer

Hasil perhitungan bobot dengan metode $A H P$, kemudian di urutkan berdasarkan total bobot dan dapat dilihat ranking seperti tabel di bawah ini.

Tabel 3 Ranking Komputer 


\begin{tabular}{|c|l|c|c|c|c|}
\hline No & \multicolumn{1}{|c|}{ Nama Komputer } & Wp ${ }^{*}$ Sp & Wd $^{*}$ Sd & Wu ${ }^{*}$ Su & Ps \\
\hline 1 & NEXTGEAR i620SA7-2377HDS-KK & 0.138 & 0.2 & 0.157 & 0.495 \\
\hline 2 & Think Centre M72e Tower 0896CTO & 0.089 & 0.2 & 0.055 & 0.446 \\
\hline 3 & Amphis BTO Di MD7300-Ci7-EX & 0.123 & 0.2 & 0.097 & 0.42 \\
\hline 4 & Pavilion Desktop PC h8-1360jp/CT & 0.104 & 0.2 & 0.097 & 0.401 \\
\hline 5 & LuvMachines Lm-iH532S Windows8 & 0.098 & 0.2 & 0.055 & 0.353 \\
\hline 7 & Compaq Elite 8300 MT/CT & 0.064 & 0.2 & 0.055 & 0.319 \\
\hline 8 & Asus Inspiron 660 & 0.064 & 0.2 & 0.055 & 0.319 \\
\hline 9 & Asus CP3130 & 0.046 & 0.2 & 0.038 & 284 \\
\hline 10 & EeeBox PC EB1501P B0047 & 0.036 & 0.2 & 0.024 & 0.26 \\
\hline Ket $=$ & Komputer yang direkomendasikandengan Metode AHP & & 0.223 \\
\hline
\end{tabular}

\subsection{Clustering dengan K-Means}

Setelah pembobotan yang didapat menggunakan AHP,tahap selanjutnya yaitu tabel akan di cluster untuk mengklasifilasi berdasarkan karakteristik bobot masing-masing komputer menggunakan algoritma k-means.

1) Perhitungan pusat jarak cluster

Tabel 4 Penentuan awal cluster di tentukan dengan metode acak

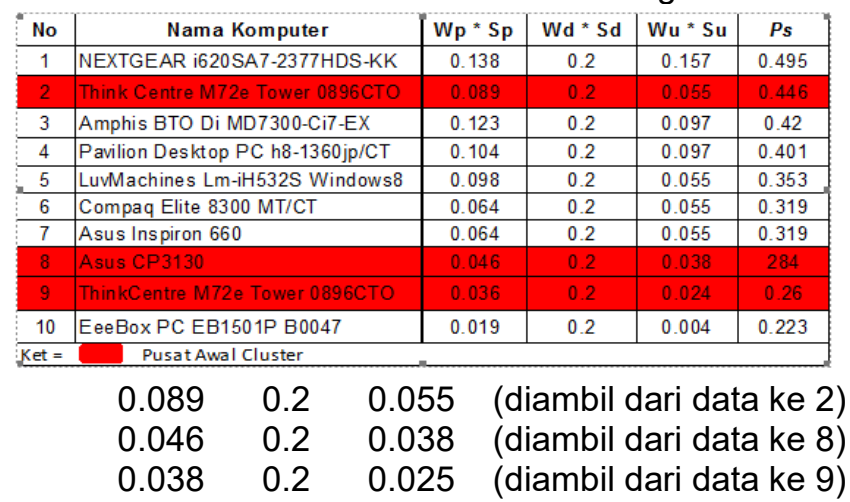

Pusat awal Cluster 1 :

Pusat awal Cluster 2 :

$\begin{array}{llll}0.038 & 0.2 & 0.025 & \text { (diambil dari data ke 9) }\end{array}$

Pusat awal Cluster 3 :

2) Perhitungan pusat jarak cluster

Setelah pemberian nama cluster untuk masing-masing data, selanjutnya akan dilakukan penghitungan untuk mendapatkan nilai centroid awal.

$$
\begin{array}{ll}
C 1=\left(\left((0.098-0.089)^{2}\right)+\left((0.2-0.2)^{2}\right)+\left((0.055-0.055)^{2}\right)\right) & C 1=0.05 \\
C 2=\left(\left((0.098-0.046)^{2}\right)+\left((0.2-0.2)^{2}\right)+\left((0.055-0.038)^{2}\right)\right) & C 2=0.055 \\
C 3=\left(\left((0.098-0.046)^{2}\right)+\left((0.2-0.2)^{2}\right)+\left((0.055-0.038)^{2}\right)\right) & C 3=0.07
\end{array}
$$

Cluster $=1 \rightarrow$ karena C1 lebih kecil dari C2 dan C3

Sehingga menghasilkan tabel seperti di bawah ini

Tabel 5 Hasil perhitungan Cluster iterasi pertama

\begin{tabular}{|r|l|r|r|r|r|r|r|r|r|}
\hline No & \multicolumn{1}{|c|}{ Nama Komputer } & $\begin{array}{c}\text { Wp }^{*} \\
\text { Sp }\end{array}$ & $\begin{array}{c}\text { Wd }^{*} \\
\text { Sd }\end{array}$ & $\begin{array}{c}\text { Wu } \\
\text { Su }\end{array}$ & C1 & C2 & C3 & Min & C \\
\hline 1 & LuvMachines Lm-iH532S Windows8 & 0.098 & 0.2 & 0.055 & 0.05 & 0.055 & 0.07 & 0.05 & 1 \\
\hline 2 & Amphis BTO Di MD7300-Ci7-EX & 0.123 & 0.2 & 0.097 & 0 & 0.097 & 0.11 & 0 & 1 \\
\hline 3 & NEXTGEAR i620SA7-2377HDS-KK & 0.138 & 0.2 & 0.157 & 0.06 & 0.15 & 0.17 & 0.06 & 1 \\
\hline 4 & Think Centre M72e Tower 0896CTO & 0.089 & 0.2 & 0.055 & 0.05 & 0.046 & 0.06 & 0.05 & 2 \\
\hline 5 & Pavilion Desktop PC h8-1360.jp/CT & 0.104 & 0.2 & 0.097 & 0.02 & 0.083 & 0.1 & 0.02 & 1 \\
\hline 6 & Compaq Elite 8300 MT/CT & 0.064 & 0.2 & 0.055 & 0.07 & 0.025 & 0.04 & 0.02 & 2 \\
\hline 7 & Asus Inspiron 660 & 0.064 & 0.2 & 0.055 & 0.07 & 0.025 & 0.04 & 0.02 & 2 \\
\hline 8 & Asus CP3130 & 0.046 & 0.2 & 0.038 & 0.1 & 0 & 0.02 & 0 & 2 \\
\hline 9 & ThinkCentre M72e Tower 0896CTO & 0.036 & 0.2 & 0.024 & 0.11 & 0.017 & 0 & 0 & 3 \\
\hline 10 & EeeBox PC EB1501P B0047 & 0.019 & 0.2 & 0.004 & 0.14 & 0.043 & 0.03 & 0.03 & 3 \\
\hline
\end{tabular}

3) Perhitungan Pusat Cluster baru

Pusat Cluster 1 Baru : $\frac{(0.098+0.123+0.138+0.104)}{4}=0.1158$

$$
\begin{aligned}
& \frac{0.2+0.2+0.2+0.2}{4}=0.2 \\
& \frac{0.055+0.097+0.157+0.097}{4}=0.1015 \\
& \text { Tabel } 6 \text { Pencarian pusat cluster baru }
\end{aligned}
$$


Sehingga :

\begin{tabular}{|c|l|c|c|c|c|r|r|r|}
\hline No & \multicolumn{1}{|c|}{ Nama Komputer } & $\begin{array}{c}\text { Wp } \\
\text { Sp }\end{array}$ & $\begin{array}{c}\text { Wd } \\
\text { Sd }\end{array}$ & $\begin{array}{c}\text { Wu } \\
\text { Su }\end{array}$ & C & $\begin{array}{c}\text { Cluster } \\
\mathbf{1}\end{array}$ & $\begin{array}{c}\text { Cluster } \\
\mathbf{2}\end{array}$ & $\begin{array}{c}\text { Cluster } \\
\mathbf{3}\end{array}$ \\
\hline 1 & LuvMachines Lm-lh532s & 0.098 & 0.2 & 0.055 & 1 & 0.1158 & 0.0658 & 0.0275 \\
\hline 2 & Amphis BTO Di MD7300 & 0.123 & 0.2 & 0.097 & 1 & 0.2 & 0.2 & 0.2 \\
\hline 3 & NEXTGEAR i620SA7-2377 & 0.138 & 0.2 & 0.157 & 1 & 0.1015 & 0.0508 & 0.014 \\
\hline 4 & Think Centre M72e Tower & 0.089 & 0.2 & 0.055 & 2 & & & \\
\hline 5 & Pavilion Des ktop PC h8- & 0.104 & 0.2 & 0.097 & 1 & & & \\
\hline 6 & Compaq Elite 8300 MT/CT & 0.064 & 0.2 & 0.055 & 2 & & & \\
\hline 7 & Asus Inspiron 660 & 0.064 & 0.2 & 0.055 & 2 & & & \\
\hline 8 & Asus CP3130 & 0.046 & 0.2 & 0.038 & 2 & & & \\
\hline 9 & ThinkCentre M72e Tower & 0.036 & 0.2 & 0.024 & 3 & & & \\
\hline 10 & EeeBox PC EB1501P & 0.019 & 0.2 & 0.004 & 3 & & & \\
\hline
\end{tabular}
Pusat Baru Cluster 1 :
$0.1158 \quad 0.2$
0.1015
Pusat Baru Cluster 2 :
$0.0658 \quad 0.2$
0.0508
Pusat Baru Cluster 3 :
0.02750 .2
0.014

Bandingkan dua hasil cluster terakhir, apabila mengalami perubahan maka lanjutkan untuk menghitung pusat cluster baru, bila dua hasil cluster terakhir tidak mengalami perubahan maka hasil cluster terakhir menjadi hasil dari proses clustering.

\subsection{Daftar Rekomendasi}

Tahap ini adalah tahap terakhir, dimana akan di ambil dua komputer dari masing masing klasifikasi dengan bobot tertinggi, sehingga daftar rekomendasi seperti tabel di bawah ini

Tabel 7 Pencarian pusat cluster baru

\begin{tabular}{|c|c|c|c|c|c|c|c|}
\hline No & Nama Komputer & CPU & GPU & Memory & HDD & Size & Usage \\
\hline 1 & $\begin{array}{l}\text { LuvMach ines Lm-iH532S } \\
\text { Windows8 }\end{array}$ & Core i7 & HD 400 & $4 \mathrm{~GB}$ & $500 \mathrm{~GB}$ & Tower & Picture \\
\hline 2 & $\begin{array}{l}\text { Amphis BTO Di MD7300- } \\
\text { Ci7-EX }\end{array}$ & Core i7 & HD 400 & $8 \mathrm{~GB}$ & $1 \mathrm{~TB}$ & Compact & Movie \\
\hline 3 & $\begin{array}{l}\text { NEXTGE AR i620SA7- } \\
2377 \text { HDS-KK }\end{array}$ & Core i7 & $\begin{array}{l}\text { GeF orce } \\
\text { GTX5 } 00\end{array}$ & $8 \mathrm{~GB}$ & $1 \mathrm{~TB}$ & Tower & Games \\
\hline 4 & $\begin{array}{l}\text { Think Centre M72e Tower } \\
\text { 0896CTO }\end{array}$ & Core is & HD250 & $4 \mathrm{~GB}$ & $1 \mathrm{~TB}$ & Tower & Picture \\
\hline 5 & $\begin{array}{l}\text { ThinkCentre M72e Tower } \\
\text { 0896CTO }\end{array}$ & $\begin{array}{c}\text { Celeron } \\
\text { G460 }\end{array}$ & HD & $2 \mathrm{~GB}$ & $250 \mathrm{~GB}$ & Tower & Offie \\
\hline 6 & $\begin{array}{l}\text { EeeB oxPC EB1501P } \\
\text { B0047 }\end{array}$ & $\begin{array}{l}\text { Atom } \\
\text { D425 }\end{array}$ & $\begin{array}{l}\text { Intel } \\
\text { GMA }\end{array}$ & $2 \mathrm{~GB}$ & $320 \mathrm{~GB}$ & Al in One & Internet \\
\hline
\end{tabular}

\section{Kesimpulan}

Berdasarkan hasil implementasi algoritma AHP dan k-means pada recommendation system, dengan menerapkan algoritma AHP dan K-Means pada data produk komputer personal, dapat menghasilkan sebuah pengetahuan berupa rekomendasi produk secara spesifik kepada pengguna.Sehingga dapat disimpulkan bahwa ternyata pengolahan data menggunakan kombinasi algoritma AHP dan K-Means menghasilkan rekomendasi produk kepada pengguna yang lebih heterogen dibandingkan dengan rekomendasi produk dari data yang diolah hanya menggunakan algoritma AHP tanpa di-cluster K-Means. Hal ini menunjukkan bahwa proses clustering akan menghasilkan kaidah-kaidah asosiasi dengan kualitas yang lebih baik. Penulis menyarankan bagi peneliti mendatang yang mengembangkan penelitian ini agar memanfaatkan algoritma pengklasteran yang lain dan dapat mengembangkan dengan menambahkan varian pengklasteran dengan variabel lain.

\section{Daftar Pustaka}

[1]. Larose, Daniel T. 2004. Discovering Knowledge in Data: An Introduction to Data Mining. John Willey \& Sons, Inc.

[2]. Han Jiawei, M. Kamber. 2006. Data Mining: Concepts and Techniques 2nd, Morgan Kaufmann, USA.

[3]. Hermawati Astuti Fajar. 2013. Data Mining. Yogyakarta: CV. Andi Offset.

[4]. Kusrini, Lutfi Taufik Emha. 2009. Algoritma Data Mining. Yogyakarta: CV. Andi Offset.

[5]. Duen Ren Liu, Ya Yueh Shih.2005.Integrating AHP and Data Mining for Product Recommendation. Information and Management 42. Science Direct.pp.387-400

[6]. Adi Nugroho, Rekayasa Perangkat Lunak menggunakan UML, Andi, Yogyakarta. 